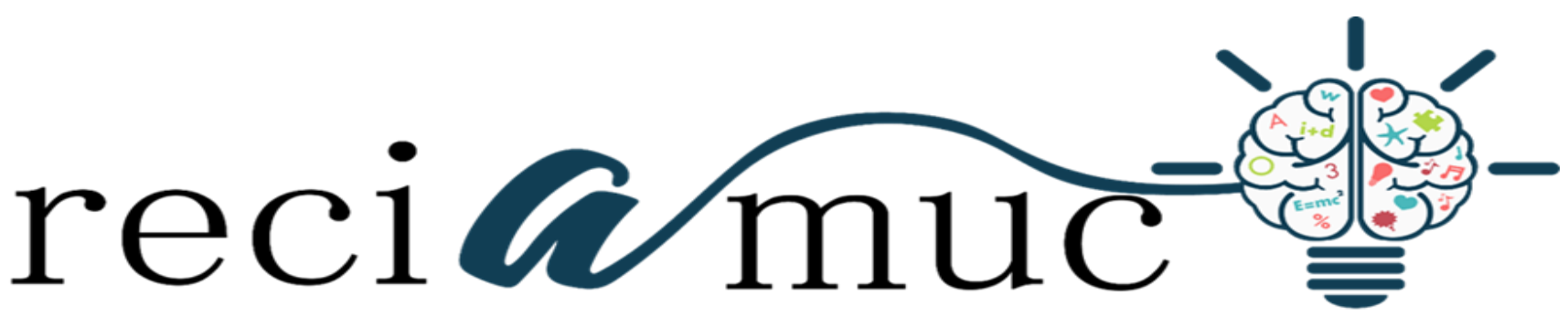

Revista cientifica de investigación actualización del mundo de las ciencias

María Cristina Alcívar Fabre a; Alfredo Enrique Galindo Veliz ${ }^{\text {b; }}$ Gianella Lissette Cruz Rambay ${ }^{\text {c}}$ P Pablo Marcelo Armas Ramírez ${ }^{\mathrm{d}}$

Cirugía de apendicitis problemas de cicatrización

Appendicitis surgery scarring problems

Revista Científica de Investigación actualización del mundo de las Ciencias. Vol. 3 núm., 1, enero, ISSN: 2588-0748, 2018, pp. 700-721

DOI: $10.26820 /$ reciamuc/3.(1).enero.2019.700-721

URL: $\underline{\text { http://reciamuc.com/index.php/RECIAMUC/article/view/253 }}$

Código UNESCO: 3205 Medicina Interna

Tipo de Investigación: Artículo de Revisión

Editorial Saberes del Conocimiento

Recibido: 10/12/2018

Aceptado: 20/01/2019

Publicado: 30/01/2019

Correspondencia: dracris.alcivarfabre@gmail.com

a. Médico; Guayaquil, Ecuador; dracris.alcivarfabre@gmail.com

b. Médico; Guayaquil, Ecuador; dr.galindovelizalfredo@gmail.com

c. Médico; Guayaquil, Ecuador; gialiss7@ @otmail.com

d. Médico; Guayaquil, Ecuador; pablo_marcelo182@hotmail.com 


\section{Cirugía de apendicitis problemas de cicatrización}

Vol. 3, núm. 1., (2019)

María Cristina Alcívar Fabre; Alfredo Enrique Galindo Veliz; Gianella Lissette Cruz Rambay;

Pablo Marcelo Armas Ramírez

\section{RESUMEN}

El diagnóstico precoz de la enfermedad y la apendicetomía inmediata con una técnica quirúrgica adecuada previenen la aparición de complicaciones posquirúrgicas y determinan el éxito del único tratamiento eficaz contra la afección más común que causa el abdomen agudo, cuyo pronóstico depende en gran medida y entre otros factores, del tiempo de evolución preoperatoria y de la fase en que se encuentre el proceso morboso al realizar la intervención. Las complicaciones de las intervenciones por apendicitis no son infrecuentes, a pesar de que los avances tecnológicos de la cirugía, anestesiología y reanimación, reducen al mínimo el traumatismo operatorio, de la existencia de salas de cuidados intensivos y cuidados intermedios, para la atención de pacientes graves y de que hoy se utilizan antibióticos cada vez más potentes. Sin embargo, no está exenta de complicaciones condicionadas por factores poco conocidos, cuya determinación podría disminuir la morbilidad y mortalidad por esta causa. No obstante, existen situaciones presente como resultado de la falla en cuanto a cicatrización post-operatoria se refiere, el paciente manifiesta serosidad sanguinolenta en la herida quirúrgica por cuerpo extraño o hemostasia deficiente, abscesos parietal e intraabdominal, hemorragia, flebitis, epiploítis, obstrucción intestinal, fístulas estercoráceas, evisceración y eventración. En consecuencia, estas apreciaciones son de interés para la realización del presente artículo, cuyo objetivo es analizar la falla de cicatrización post operatoria en apendicitis, el mismo corresponde a una investigación documental, con apoyo bibliográfico e incorporación de técnicas caracterizadas por marcar las condiciones para una lectura rápida y coherente, con el fin de llegar finalmente a construir las conclusiones.

Palabras Claves: Falla de Cicatrización; Post-Operatoria; Apendicitis. 


\title{
Cirugía de apendicitis problemas de cicatrización
}

Vol. 3, núm. 1., (2019)

María Cristina Alcívar Fabre; Alfredo Enrique Galindo Veliz; Gianella Lissette Cruz Rambay; Pablo Marcelo Armas Ramírez

\begin{abstract}
Early diagnosis of the disease and the immediate appendectomy with a proper surgical technique prevents the emergence of post-surgery complications and determine the success of the only effective treatment against the most common condition causing acute abdomen, whose prognosis depends on heavily and inter alia, preoperative evolution and time of the phase in which the morbid process is to perform the operation. Interventions for appendicitis complications are not uncommon, while technological advances in surgery, Anesthesiology and resuscitation, minimize surgical trauma, the existence of care and intensive care rooms intermediate, for the care of ill patients and that today increasingly powerful antibiotics are used. However, it is not free of complications conditioned by little-known factors, whose determination could decrease morbidity and mortality from this cause. However, there are situations present as a result of the failure referred to in terms of post-operative healing, the patient says bloody serosity in the surgical wound by foreign body or poor hemostasis, abscesses parietal e intra-abdominal, hemorrhage, bowel obstruction, phlebitis, epiploitis, estercoráceas and evisceration, eventration fistulas. Consequently, these findings are of interest for the implementation of this article, whose objective is to analyze the failure of healing post-operative in appendicitis, it corresponds to a documentary research, with bibliographic support and incorporation of techniques characterized by Mark conditions for reading quickly and coherently, in order to finally become the conclusions.
\end{abstract}

Key Words: Failure; Healing-Post-Operatoria; Appendicitis. 


\section{Cirugía de apendicitis problemas de cicatrización}

Vol. 3, núm. 1., (2019)

María Cristina Alcívar Fabre; Alfredo Enrique Galindo Veliz; Gianella Lissette Cruz Rambay;

Pablo Marcelo Armas Ramírez

\section{Introducción.}

El trabajo de los especialistas en las diferentes áreas médicas, se realiza mediante prácticas centradas en llevar a cabo un diagnóstico que le permita determinar las condiciones básicas del paciente. Por ello, los cirujanos al momento de realizar una operación quirúrgica realizan una serie de evaluaciones clínicas, laboratorio y en algunos casos pruebas de imágenes para tener un diagnóstico preciso y coherente a la sintomatología manifestada por el paciente. En el caso particular, de la apendicitis, puede ser realizada mediante una cirugía abierta o laparoscopia, todo depende de los resultados obtenidos durante las evaluaciones correspondientes.

Cabe destacar que, la apendicectomía puede realizarse como una cirugía abierta, haciendo una incisión en el abdomen de 2 a 4 pulgadas (de 5 a $10 \mathrm{~cm}$ ) de largo aproximadamente (laparotomía). O bien, la cirugía a través de unas incisiones pequeñas en el abdomen (cirugía laparoscópica). Durante una apendicectomía laparoscópica, el cirujano inserta instrumentos quirúrgicos especiales y una videocámara en el abdomen para extraer el apéndice. En general, la cirugía laparoscópica permite al paciente recuperarte rápido, sanar con menos dolor y cicatrices. Puede ser una mejor opción para personas mayores u obesas. Sin embargo, esta cirugía no es adecuada para todos; pues, al encontrar que el apéndice se perforó y la infección se extendió más allá del apéndice o si tienes un absceso, es posible necesitar una apendicectomía abierta, la cual le asegura al cirujano limpiar la cavidad abdominal.

En este sentido, la Enciclopedia Médica (2016) define el apéndice “como un órgano pequeño en forma de tubo, unido a la primera parte del intestino grueso. Ubicado en la parte 


\section{Cirugía de apendicitis problemas de cicatrización}

Vol. 3, núm. 1., (2019)

María Cristina Alcívar Fabre; Alfredo Enrique Galindo Veliz; Gianella Lissette Cruz Rambay; Pablo Marcelo Armas Ramírez

inferior del abdomen y no tiene ninguna función conocida" (p. 66). Según este concepto, se deducir, que la apendicitis es causada por un bloqueo en el interior del apéndice. Este bloqueo provoca un aumento de la presión, problemas con el flujo de la sangre e inflamación. Si el bloqueo no se trata, el apéndice puede romperse y diseminar la infección hacia el abdomen. Esta afección se llama peritonitis.

Es importante acotar, que durante la infancia, la función del apéndice es producir células de defensa, pero a lo largo de la vida pierde esta función. En ocasiones se desconoce el origen de su inflamación. Una de las explicaciones es la presencia de cuerpos extraños que causan obstrucción, produciéndose una disminución en la oxigenación en el tejido del apéndice, ulceración y posterior invasión de bacterias. Por ello, el método de diagnóstico más importante de apendicitis aguda, es la evaluación realizada por el médico, quien a partir del examen físico realizado al paciente e interrogatorio acerca del dolor y síntomas asociados, puede sospechar la causa del cuadro clínico, para descartar otro tipo de entidades. Los pacientes con diagnóstico de apendicitis aguda deben ser hospitalizados y evaluados por un especialista en cirugía, quien realizará el manejo quirúrgico.

Sin embargo, Montes (2018), destaca que "el tratamiento más común para la apendicitis es una apendectomía o cirugía para remover completamente el apéndice. No obstante, en algunos pacientes, el apéndice puede romperse y llevar a la formación de un absceso o colección de pus”. (p.12). Estas ideas, llevan a comprender que cuando el médico cirujano, se encuentra con un paciente que presenta peritonitis, la cirugía debe ser más larga y por ende realizar una incisión mayor en la mitad del abdomen que le permita llevar a cabo la respectiva limpieza de dicha cavidad, para así, evitar consecuencias posteriores. 


\section{Cirugía de apendicitis problemas de cicatrización}

Vol. 3, núm. 1., (2019)

María Cristina Alcívar Fabre; Alfredo Enrique Galindo Veliz; Gianella Lissette Cruz Rambay; Pablo Marcelo Armas Ramírez

Ante estos acontecimientos, el abordaje a la terapia antibiótica después de la apendicectomía es variado. Muchos cirujanos eligen tratar a los pacientes con apendicitis complicada con un curso predefinido de antibióticos intravenosos (IV) u orales, mientras que otros guiarán la ruta y duración de la terapia sobre la base de los síntomas y signos clínicos, incluyendo la resolución del íleo, normalización del recuento de glóbulos blancos y ausencia de fiebre. Para Montes (ob.cit) "en la actualidad, no existe un consenso en relación con el momento óptimo ni la duración de la antibioticoterapia para los pacientes con apendicitis complicada". (p.23)

De estas apreciaciones, se desprende que la profilaxis antibiótica es efectiva en la prevención de complicaciones postoperatorias en pacientes apendicectomizados si la administración es dada pre, per o postoperatoriamente y debería ser considerada para su uso de rutina en la apendicetomía de emergencia. Pues, el impacto de los antibióticos postoperatorios sobre las complicaciones infecciosas en los pacientes con atención quirúrgica de urgencia por variados procesos patológicos ha sido previamente investigado. Es así como, Altrudi (2017) destaca que:

Los antibióticos postoperatorios no están asociados con una disminución en la incidencia de complicaciones de la herida quirúrgica entre los pacientes sometidos a apendicectomía por apendicitis complicada. Son necesarios estudios futuros multiinstitucionales prospectivos para determinar la eficacia del uso de antibióticos postoperatorios para reducir la incidencia de complicaciones en la herida en los pacientes con apendicitis complicada.(p.25) 


\section{Cirugía de apendicitis problemas de cicatrización}

Vol. 3, núm. 1., (2019)

María Cristina Alcívar Fabre; Alfredo Enrique Galindo Veliz; Gianella Lissette Cruz Rambay; Pablo Marcelo Armas Ramírez

De acuerdo, con lo planteado por Altrudi, se precisa que cuando se presentan complicaciones post- operatoria luego de una apendicetomía, el médico tratante, puede considerar el uso del antibiótico como un medicamento que ayuda a reducir las complicaciones; pero su utilización según lo citado, no se convierten en medidas esenciales, hay necesidad de estudiar de forma particular, las dolencias manifestadas por el paciente, a fin de manejar de manera efectiva su uso o buscar otra vía que ayuda a mejorar las condiciones de salud en el paciente.

Por lo tanto, las complicaciones que puedan manifestar los pacientes en relación a la cicatrización post operatoria de una apendicitis, son como posibles eventualidades en el curso del procedimiento quirúrgico con una respuesta local o sistémica que puede retrasar la recuperación del paciente o poner en riesgo su vida. Por ello, las consideraciones, de incorporar el uso de los antibióticos, se hace cada vez más importante, mediante su manejo efectivo, puede lograrse una mejoría en las condiciones de salud. Asimismo, el médico puede, al realizar una evaluación de la herida y al encontrar pus o secreción, mal olor, fiebre, enrojecimiento y dolor al tocar, es importante recurrir al uso del drenaje como una alternativa que ayuda a la expulsión de la secreción o pus.

Al continuar, con las consideraciones anteriores y con el fin de apoyar referencialmente las fallas de cicatrización post operatoria en una apendicitis, es importante considerar lo expuesto por Salvatierra (2018) quien destaca que:

La cirugía que involucra un corte (incisión) en la piel puede llevar a una infección en la herida tras la operación, su mayoría se presentan en los primeros treinta días 


\section{Cirugía de apendicitis problemas de cicatrización}

Vol. 3, núm. 1., (2019)

María Cristina Alcívar Fabre; Alfredo Enrique Galindo Veliz; Gianella Lissette Cruz Rambay;

Pablo Marcelo Armas Ramírez

después de la cirugía. Las mismas, pueden estar rojas y despidiendo pus, doler o estar calientes al tacto. (p.6)

En función a esta descripción, se precisa que cuando un paciente ha sido sometido a una cirugía de apendicetomía, su etapa de recuperación puede ser vista con posibles fallas en cuanto a la cicatrización se refiere, pues, el paciente como resultado a una serie de dolencias como fiebre, malestares generales, al consultar al médico y éste diagnosticarlo puede encontrarse con la presencia de olores, enrojecimiento en la herida, asimismo, al momento de tocar el abdomen de la herida puede salir pus. Conjunto de síntomas, que amerita una nueva intervención del médico, con la finalidad de darle la respectiva atención para lograr su recuperación.

Cada una de las apreciaciones citadas, permiten considerar el planteamiento de Molina (2018) quien indica que:

En los últimos 50 años ha ocurrido un dramático descenso de la mortalidad asociada a la apendicitis aguda (desde 26,0 hasta menos del 1,0 \%). Sin embargo, la morbilidad todavía hoy refleja una alta incidencia de perforaciones $(17,0$ al 20,0 \%) a pesar de los diagnósticos realizados por imágenes y del desarrollo biotecnológico alcanzado. (p.12)

De lo planteado, se entiende que la presencia de la falla de cicatrización post operatoria de una apendicitis, debido a los avances científicos e investigativos que existen hoy en día en el campo de la medicina, son escaso; pero hay una alta incidencia en cuanto a perforaciones se refiere, lo que amerita, la atención inmediata del médico, para así lograr no sólo mejorar, sino reducir los posibles riesgos post operatorios que puedan afectar la vida del paciente. 


\section{Cirugía de apendicitis problemas de cicatrización}

Vol. 3, núm. 1., (2019)

María Cristina Alcívar Fabre; Alfredo Enrique Galindo Veliz; Gianella Lissette Cruz Rambay; Pablo Marcelo Armas Ramírez

Cabe destacar que, la posible falla en cuanto a cicatrización se refiere post operatoria en un paciente operado de apendicitis, las mismas pudieran estar presentándose por la presencia de microbios que se encuentran en la piel, los cuales se propagan a la herida quirúrgica, otros están dentro del cuerpo o provienen del organismo en el que se realizó la cirugía, asimismo, la infección solo está en la zona de piel; también puede ser profunda: la infección va más allá de la piel hasta el músculo y el tejido que puede comprometer al órgano y espacio en los que se le realizó la cirugía, de igual manera, se encuentran los microbios que se encuentran en el ambiente a su alrededor como los instrumentos quirúrgicos o en las manos del proveedor de atención médica.

De este modo, se puede decir que las fallas de cicatrización post operatoria en una apendicitis, resultan un tema de interés para el desarrollo de este artículo, mediante el cual se busca analizar los diferentes aportes teóricos que de una u otra manera, sirven de referencia para generar nuevas consideraciones generales y en de pro de ello responder de manera eficaz al objetivo trazado, así como, al método considerado para su conducción metodológico.

\section{Método.}

Para la realización de este contenido que estructura el desarrollo del presente artículo, se hizo necesario cumplir con una revisión bibliográfica, mediante el cual se pudo leer artículos de revistas médicas, tanto en su formato impreso como digital, En el caso de las revistas en formato impreso se utilizó el fichero existente, haciendo la búsqueda por títulos de artículo usando las mismas palabras claves. Actividades que dieron cabida a la selección del método encargado de orientar la investigación hacia una correspondencia temática. 


\section{Cirugía de apendicitis problemas de cicatrización}

Vol. 3, núm. 1., (2019)

María Cristina Alcívar Fabre; Alfredo Enrique Galindo Veliz; Gianella Lissette Cruz Rambay; Pablo Marcelo Armas Ramírez

Según Kerlinger (2015) el método científico es “el estudio sistemático, controlado, empírico y crítico de proposiciones hipotéticas acerca de presuntas relaciones entre varios fenómenos”. (p.22). Es decir, mediante la utilización del método, se pudo lograr una organización sistemática de la información requerida para el proceso investigativo, para así llegar a postular las respectivas vinculaciones existentes entre las características que identifican al fenómeno en estudio.

Por lo tanto, para el desarrollo del artículo se incorporó el método inductivo, definido por Kerlinger (ob.cit) "como la disgregación de los aspectos estructurales de un hecho y luego organizados en un todo para su interpretación general".(p. 24). Esto indica claramente, que mediante su utilización el investigador pudo, preparar los contenidos desde una visión individual, valorarlos como parte esencial del proceso, para luego convertirlos en apreciaciones generales que dieron cabida a la construcción de las conclusiones del artículo.

\section{Tipo de Investigación}

Para darle respuesta al objetivo que estructura al presente artículo, se hizo necesario establecer la vinculación con una naturaleza investigativa, visto por Zambrano (2018) "como la recopilación de informaciones provenientes de materiales impresos, audiovisuales, tecnológicos entre otras, para expresar nuevas ideas acerca de un tema en particular".(p.33). Es decir, mediante este tipo de investigación, se puede replantear nuevas valoraciones referidas a un contenido en particular, que hace posible conjugar diferentes interpretaciones para finalmente complementar sus beneficios dentro de una teoría en particular. 


\section{Cirugía de apendicitis problemas de cicatrización}

Vol. 3, núm. 1., (2019)

María Cristina Alcívar Fabre; Alfredo Enrique Galindo Veliz; Gianella Lissette Cruz Rambay; Pablo Marcelo Armas Ramírez

\section{Fuentes Documentales}

La conducción de la dinámica científica amerita para ser viable a un proceso veraz el complemento de aquellas fuentes documentales que le dan oportunidad de encontrar de forma precisa el respectivo dominio de un fenómeno de acuerdo con sus características especiales que le asignan un conocimiento enmarcado en una realidad previa. En tal sentido Zambrano (ob.cit) destaca que las fuentes documentales "es la suma de técnicas que permiten orientar el trabajo desde una perspectiva cotidiana para cumplir con los diferentes procedimientos mediante explicaciones”.(p.35). Por lo tanto, su aplicación en el proceso investigativo, permite asegurar con antelación, la revisión de diferentes documentos propios y relacionados con el tema, para luego elaborar su contenido que quedará como representación del fenómeno en estudio.

\section{Técnicas para la Recolección de la Información}

Con el fin de darle operatividad al presente proceso investigativo, se busca primeramente plantear la definición de técnica dada por Zambrano (ob.cit) "son los diferentes procedimientos para el aprovechamiento científico de los elementos de la naturaleza y sus derivados”.(p.35). Según lo citado, permite interpretar que darle la respectiva complejidad al análisis que se busca del tema previo, se hace necesario adecuar las apreciaciones en función a los procedimientos que den cabida a un mayor aprovechamiento de los elementos presente en la naturaleza del tema seleccionado.

De este modo, durante la fase de recolección de la información, se llevaron a cabo acciones especiales que dieron cabida a incorporar las técnicas de fuentes de información definidas por Zambrano (ob.cit) “como aquellas herramientas básicas para las investigaciones 


\section{Cirugía de apendicitis problemas de cicatrización}

Vol. 3, núm. 1., (2019)

María Cristina Alcívar Fabre; Alfredo Enrique Galindo Veliz; Gianella Lissette Cruz Rambay; Pablo Marcelo Armas Ramírez

documentales que conllevan al uso óptimo y racional de los recursos documentales" (p.35). En consecuencia mediante su utilización, se puede organizar los diferentes contenidos desde las fuentes de información primaria (libros), para luego continuar con la revisión de documentos impresos que dieron oportunidad de referenciar las teorías de manera explícita a los contenidos temáticos.

De acuerdo con los planteamientos anteriores, se puede decir que mediante la utilización de las técnicas documentales las actividades inherentes al proceso investigativo, puede ser llevadas a cabo, sin generar dificultades para dar la respectiva valoración que el momento científico presenta. Es decir, se procedió a una organización coherente de los aspectos más significativos que forman parte de la recopilación de información. Por ello, la Es importante destacar que para la organización de los diversos contenidos expuestos en el marco teórico referencial de la investigación y llevarlos a su análisis e interpretación, condujo al autor del estudio a buscar aquellos elementos básicos que darán como resultado todo un análisis e interpretación en los estudios documentales responde a la distribución temática que presentan los objetivos, para lo cual, se desarrolla un aparato crítico conformado por notas textuales, de citas y referencias.

\section{Resultados.}

Los hallazgos encontrados a lo largo de la revisión bibliográfica, llevada a cabo se pueden indicar diferentes aportes significativos relacionados con los elementos caracterizados por el desarrollo de los eventos propios que estructuran el contenido investigativo hacia una 


\section{Cirugía de apendicitis problemas de cicatrización}

Vol. 3, núm. 1., (2019)

María Cristina Alcívar Fabre; Alfredo Enrique Galindo Veliz; Gianella Lissette Cruz Rambay; Pablo Marcelo Armas Ramírez

dirección metodológica previamente preestablecida, entre ellos se encuentran a continuación los siguientes argumentos.

\section{Falla de Cicatrización Post Operatoria en Apendicitis}

La apendicitis se refiere a la inflamación del apéndice. La apendicectomía, la extracción quirúrgica del apéndice, se realiza principalmente en pacientes que presentan apendicitis aguda. Los pacientes sometidos a una apendicectomía para la apendicitis complicada, que se define como apendicitis gangrenosa (muerte del tejido blando) o perforada (rotura), tienen mayor probabilidad de sufrir complicaciones posoperatorias. La colocación sistemática de un drenaje quirúrgico para prevenir el absceso intraperitoneal (una colección localizada de pus en el abdomen o la pelvis) después de una apendicectomía para la apendicitis complicada es polémica.

Figura $N^{\circ} 1$ Ubicación de la Apéndice.

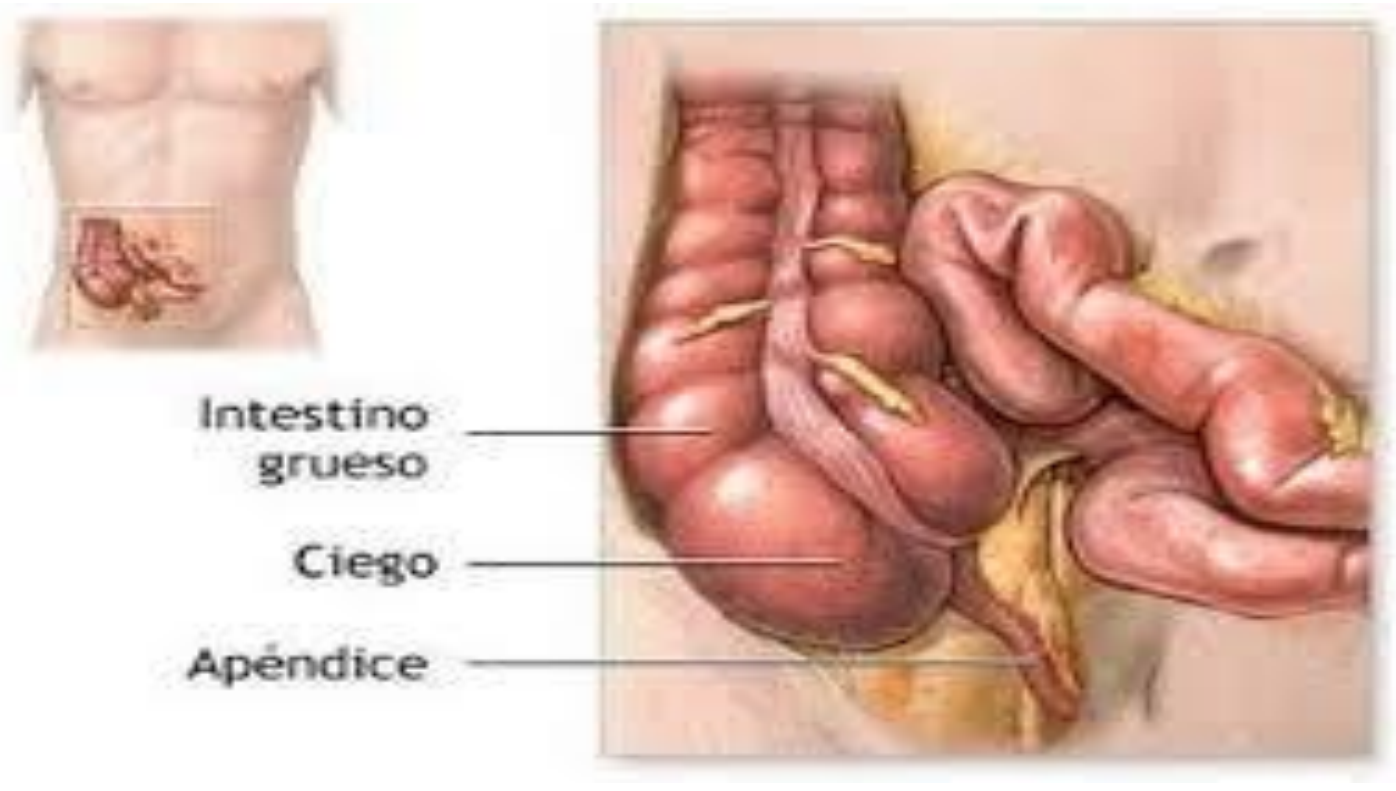

Fuente: Elaboración Propia 


\section{Cirugía de apendicitis problemas de cicatrización}

Vol. 3, núm. 1., (2019)

María Cristina Alcívar Fabre; Alfredo Enrique Galindo Veliz; Gianella Lissette Cruz Rambay; Pablo Marcelo Armas Ramírez

De lo antes descrito, se puede decir que no hay cirujano que no tenga que afrontar el problema de las complicaciones que pueden presentarse en los pacientes que ha sometido a intervención quirúrgica. Estas posibles complicaciones están referidas a: dehiscencia de la herida, dolor de la herida, acumulación de suero, hemorragia, senos de las líneas de sutura, infección de la herida, cicatrices hipertróficas, queloides, eventraciones. Cabe destacar que, cuando existe una falla de cicatrización post operatoria en apendicitis, según Padrino (2017) se encuentran diferentes fallas entre ellas:

- Hemorragia de Herida Operatoria: Ocurre más frecuentemente en pacientes hipertensos o con defectos de coagulación. El hematoma de las heridas es casi siempre resultado de hemorragia controlable por medios quirúrgicos. Una vez detectado, se debe reabrir la herida, identificar el o los vasos sangrantes y ligarlos. Otras veces es consecuencia de una hemostasia no muy prolija, antes de cerrar definitivamente la herida.

- Acumulación de Suero Es frecuente en heridas que tienen un gran espacio muerto como las de las mastectomías o la de los pacientes obesos. Se las trata mediante la aspiración, o si es voluminosa, mediante una herida por transfixión en el punto más declive aplicando luego un dren con un apósito de compresión. La evacuación debe hacerse lo más precozmente, ya que con frecuencia son asiento de infección.

- Dehiscencia de la Herida: La frecuencia de esta complicación varía mucho en función de cirujano, paciente y tipo de operación. En una herida abdominal, la dehiscencia total produce evisceración y la dehiscencia parcial profunda conduce a la eventración. 


\section{Cirugía de apendicitis problemas de cicatrización}

Vol. 3, núm. 1., (2019)

María Cristina Alcívar Fabre; Alfredo Enrique Galindo Veliz; Gianella Lissette Cruz Rambay; Pablo Marcelo Armas Ramírez

En la mayoría de casos de dehiscencia, se encuentra que los puntos han desgarrado el tejido. Posiblemente el error más frecuente que condiciona una dehiscencia sea el tensionar demasiado los puntos que van a estrangular los bordes suturados comprometiendo la circulación en esta zona, asimismo los puntos flojos o mal anudados, demasiados puntos, toma de muy poco tejido o material de sutura inapropiado, son otras causas de dehiscencia.

- Senos de las líneas de Sutura: Cuando el material de sutura no absorbible se infecta, se forma el llamado granuloma a cuerpo extraño, que se abre camino hacia la superficie y después de formar una pequeña tumoración fluctuante, drena material mucopurulento, estableciéndose de esa manera seno o senos en cuyo fondo se encuentra el material de sutura referido, que a veces es expulsado espontáneamente pero que la mayor parte de veces, requiere la introducción de una pinza de punta fina para explorar y extirparlo. De persistir el seno es preferible abrir la porción de herida comprometida, extraer todo el material de sutura que se encuentra en ese lugar y dejar la herida abierta para cierre por segunda intención.

- Infección: Las manifestaciones de infección de herida operatoria aparecen generalmente entre el tercero y décimo días del post operatorio, aunque con menos frecuencia pueden aparecer antes o después. El tejido celular subcutáneo es el más frecuentemente comprometido. La manifestación más frecuente es la fiebre, puede haber aumento de dolor en la herida así como edema y eri-tema. Prevenir la infección de la herida operatoria es uno de los aspectos más importantes en el cuidado del 


\section{Cirugía de apendicitis problemas de cicatrización}

Vol. 3, núm. 1., (2019)

María Cristina Alcívar Fabre; Alfredo Enrique Galindo Veliz; Gianella Lissette Cruz Rambay; Pablo Marcelo Armas Ramírez paciente, esto puede conseguirse reduciendo la contaminación, con técnica quirúrgica limpia y suave, sostén de las defensas del paciente y a veces antibióticos.

- Infecciones en Cirugía: Se denomina infecciones quirúrgicas a todas aquellas que se originan por gérmenes bacterianos y/o por los hongos como consecuencia de un acto quirúrgico, presentándose la patología infecciosa en el periodo inmediato o mediato a la intervención.

\section{Figura $N^{\circ} 2$ Infecciones en Cirugía}

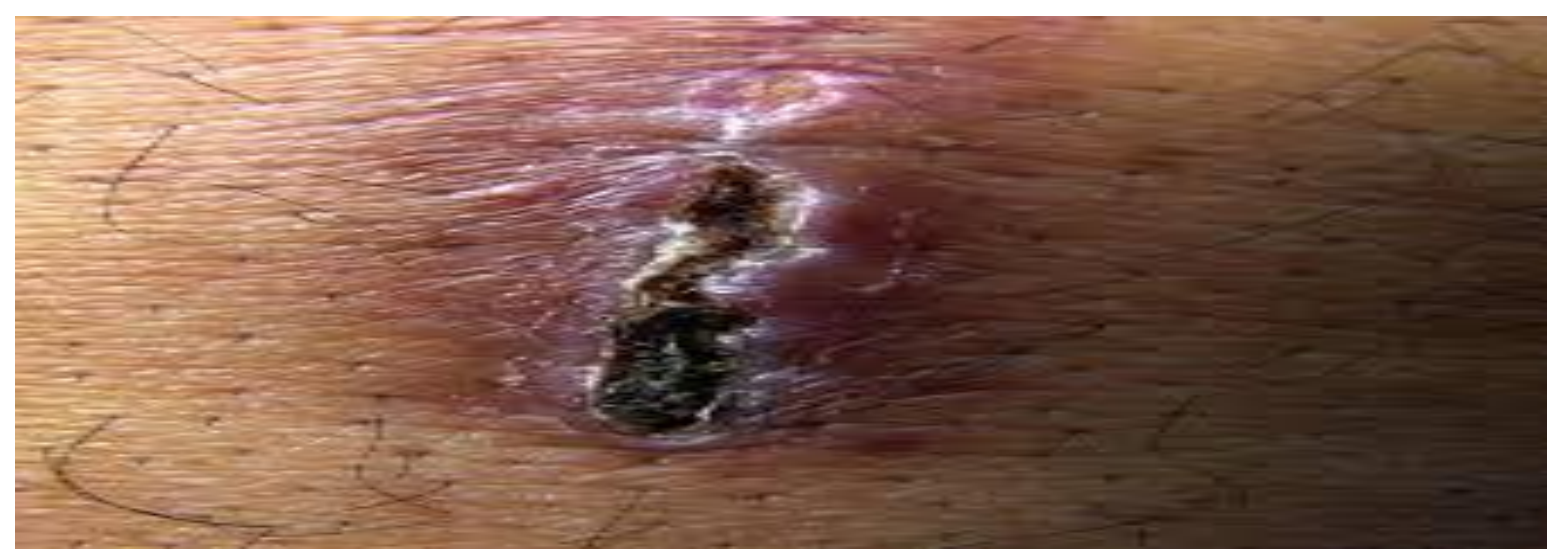

Fuente: Elaboración Propia (2019).

En este orden de ideas, el autor citado, precisa que la infección quirúrgica puede originarse en una cirugía séptica o aséptica. Puede ser endoinfección o exoinfección, monobacteriana o polibacteriana, toxígena, nicótica o mixta.Se denomina endoinfección quirúrgica a la sepsis focal o general producida a raíz de una cirugía séptica o aséptica, por invasión de los agentes correspondientes a las cepas indígenas que pueblan la encrucijada 


\section{Cirugía de apendicitis problemas de cicatrización}

Vol. 3, núm. 1., (2019)

María Cristina Alcívar Fabre; Alfredo Enrique Galindo Veliz; Gianella Lissette Cruz Rambay; Pablo Marcelo Armas Ramírez

aerodigestiva, enterocolónica o vía genitourinaria baja, y que adquieren protopatogenicidad por el acto quirúrgico o ciertas terapéuticas o modificaciones del terreno o estados clínicos especiales, llegando a producir cuadros sépticos mono o polibacterianos o micopatías localizadas o generalizadas.

Al hacer referencia a la exoinfección quirúrgica a la sepsis focal y/o general producida a raíz de un acto quirúrgico en un medio quirúrgico, por invasión del o de los gérmenes que rodean al enfermo en su hábitat y que alcanzan al huésped por diferentes vías, sean a erógenas, digestivas, por inoculación o por contacto íntimo.Las infecciones postquirúrgicas se sintetizan en tres síndromes: infeccioso focal, infeccioso general, bacteriano sin sepsis e infeccioso focal, se produce cuando una asociación de gérmenes bacterianos, cocos Gram positivos o gramnegativos o bien colonias mono bacterianas: estreptococos, estafilococos, piociánicos, aerobacter, proteus, etc. desencadenan la supuración de la herida operatoria. A esto se puede agregar las miopatías como simple asociación, o asociación más infección nicótica: cándidas, aspergillus o macor.

\section{Figura $N^{\circ} 3$ Exoinfección Quirúrgica.}

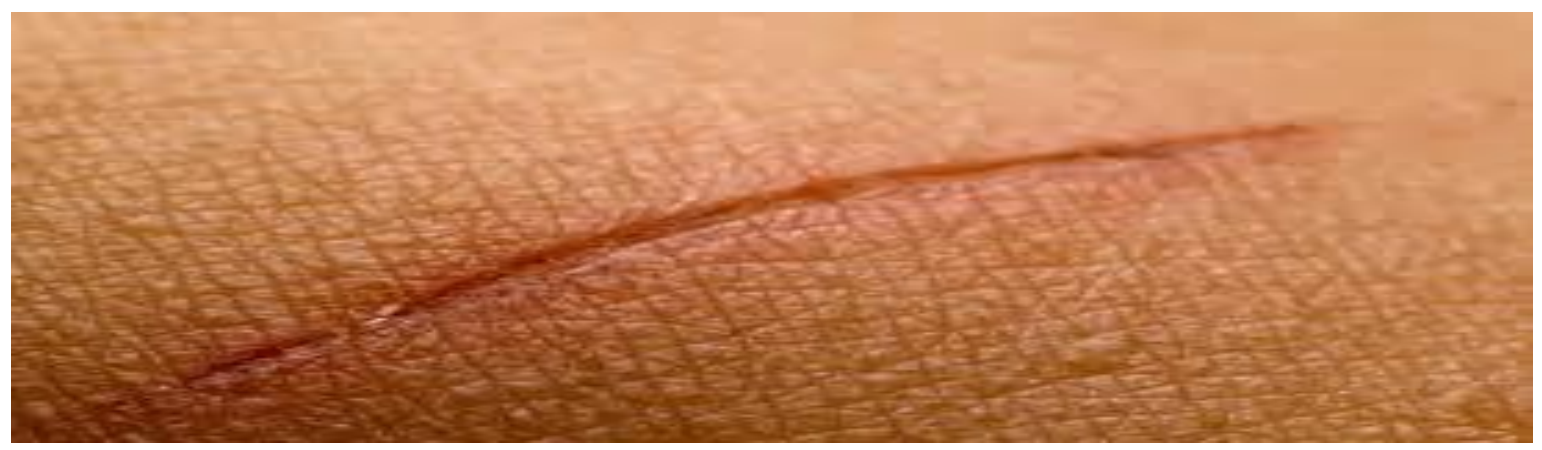

Fuente: Elaboración Propia (2019) 


\section{Cirugía de apendicitis problemas de cicatrización}

Vol. 3, núm. 1., (2019)

María Cristina Alcívar Fabre; Alfredo Enrique Galindo Veliz; Gianella Lissette Cruz Rambay; Pablo Marcelo Armas Ramírez

En cuanto a la etiología de la infección del lecho quirúrgico, Padrino (ob.cit), destaca que tiene relación, en la mayoría de los casos con el tipo de intervención y órgano o sistema afectado. Entre ellas, se encuentran:

- Eventración: La Eventración puede deberse a un punto flojo o a uno que está demasiado apretado y ha estrangulado y cortado el tejido que engloba la infección o a una dehiscencia. La reparación de estas eventraciones debe llevarse a cabo después de los seis meses por lo menos, la reparación temprana lleva a la reaparición del problema. Debe evitarse suturar los tejidos sometiéndolos a mucha tensión teniendo entonces que recurrir incluso a las incisiones relajantes. En ocasiones tal vez sea necesario recurrir al uso de malla de marlex.

- Complicaciones Hemorrágicas: Ocurren en el postoperatorio inmediato, cursan muchas veces en forma catastrófica llevando al shock hipovolémico lo que lleva a una reintervención inmediata. Otras veces es menos aguda y permite control adecuado de funciones vitales, administración de fluidos, etc. antes de reintervenir.

- Anomalías de la hemostasia: deben ser identificadas en el preoperatorio. La causa más común de hemorragia intra o postoperatoria en un paciente con historia clínica y examen físico negativos, además de pruebas de laboratorio normales, es la falla en la ligadura de vasos sanguíneos seccionados.

Con respecto a los planteamientos, anteriores se puede decir que la apendicitis aguda es el cuadro quirúrgico de urgencia abdominal más frecuente. Según Salvatierra (ob.cit) existe en las estadísticas mundiales, es la causa principal del abdomen agudo quirúrgico. Es una de las 


\section{Cirugía de apendicitis problemas de cicatrización}

Vol. 3, núm. 1., (2019)

María Cristina Alcívar Fabre; Alfredo Enrique Galindo Veliz; Gianella Lissette Cruz Rambay; Pablo Marcelo Armas Ramírez

entidades clínicas mejor reconocidas, pero una de las que mayores problemas diagnósticos pueden suponer para el clínico, constituye un desafío único y a veces frustrante. Del 7 al 12\% de la población general padece apendicitis aguda en algún momento de su vida. Es una enfermedad poco frecuente en menores de 7 años. Alcanza su mayor frecuencia en personas entre los 15 y los 25 años. Menos del $2 \%$ de las apendicitis pediátricas se presentan en lactantes y es extremadamente rara en neonatos.

Es una enfermedad más grave en lactantes y niños que en adultos, porque el índice de ruptura es más alto (excede el 50\% en menores de 6 años 1), lo que a su vez origina mayor morbilidad y mortalidad. La precisión diagnóstica de apendicitis aguda en niños es mucho más baja que en adultos. A ello contribuye un cuadro clínico menos típico, con fiebre alta y vómitos, también el aspecto de que los lactantes no pueden proporcionar una historia de la enfermedad actual, y la falla del médico de no considerarla por su relativa rareza en los muy pequeños. El retraso en su diagnóstico y factores como la delgadez relativa de la pared del apéndice en los pacientes pediátricos, y el hecho de que el epiplón es más corto, por lo que no alcanza a obliterar y delimitar la zona de inflamación, contribuyen a que los niños sufran peritonitis generalizada y gangrena más precozmente.

De lo antes expuesto, se puede indicar que la apendicectomía por apendicitis aguda es una intervención quirúrgica urgente muy frecuente. En la práctica clínica, la indicación es realizada por el cirujano cuyo diagnóstico, aunque puede apoyarse en exploraciones complementarias (laboratorio, ecografía y tomografía axial computarizada), es básicamente clínico y depende de sus conocimientos, y de su experiencia. Aunque la población que se interviene por esta enfermedad es mayoritariamente joven y con escasa comorbilidad, también 


\section{Cirugía de apendicitis problemas de cicatrización}

Vol. 3, núm. 1., (2019)

María Cristina Alcívar Fabre; Alfredo Enrique Galindo Veliz; Gianella Lissette Cruz Rambay; Pablo Marcelo Armas Ramírez

puede presentarse en pacientes de edad avanzada con enfermedades asociadas de riesgo. Es un acto quirúrgico que no debe considerarse menor, a pesar de su brevedad y de la sencillez de su ejecución en la mayoría de los casos. La posibilidad de desarrollo de complicaciones postoperatorias no es irrelevante, ya que se trata de un proceso séptico intraperitoneal. Los retrasos en el diagnóstico o en el tratamiento condicionan la presentación de apendicitis evolucionadas con peritonitis difusa o localizada.

Esto permite destacar que, la apendicitis frecuentemente comprende los rangos de edad entre los veinte y treinta años de vida, del total de pacientes un 5 al $10 \%$ son los adultos mayores; en los mayores de 60 años de edad, esta patología se incrementado en las últimas décadas. La apendicitis corresponde entre el 2.5\% a 5\% de las patologías de Abdomen Agudo Quirúrgico en los pacientes adultos mayores. Por lo tanto, las fallas de cicatrización, aunque son escasas en los jóvenes, tiene una mayor tendencia en las personas mayores todo ello depende de las condiciones orgánicas del paciente.

\section{Conclusiones.}

El análisis realizado a lo largo del proceso investigativo, permite llegar a la exposición de una serie de apreciaciones caracterizadas por valorar los aportes ofrecidos durante el desarrollo del tema, entre las cuales se citan las siguientes:

La apendicitis aguda es una de las urgencia, la misma debido a sus características de manifestación de la sintomatología, debe ser precisada mediante la realización de un diagnóstico, donde no sólo se considere la experiencia del médico, sino buscar mediante imágenes, exámenes de laboratorios entre otros, una valoración cónsona a las situaciones indicadas por el paciente, 


\section{Cirugía de apendicitis problemas de cicatrización}

Vol. 3, núm. 1., (2019)

María Cristina Alcívar Fabre; Alfredo Enrique Galindo Veliz; Gianella Lissette Cruz Rambay; Pablo Marcelo Armas Ramírez

con el fin de garantizar con ello efectividad en su recuperación. Cabe agregar, que la apendicitis es una inflamación del apéndice, una bolsa en forma de dedo que se proyecta desde el colon en el lado inferior derecho del abdomen. El apéndice no parece tener un propósito específico. Provoca dolor en el abdomen bajo derecho. Sin embargo, en la mayoría de las personas, el dolor comienza alrededor del ombligo y luego se desplaza. A medida que la inflamación empeora, el dolor de apendicitis por lo general se incrementa y finalmente se hace intenso

Por ello, la apendicectomía por apendicitis aguda es una intervención quirúrgica urgente frecuente. En la práctica clínica, la indicación es realizada por el cirujano cuyo diagnóstico, aunque puede apoyarse en exploraciones complementarias (laboratorio, ecografía y tomografía axial computarizada), es básicamente clínico y depende de sus conocimientos, y de su experiencia. Aunque la población que se interviene por esta enfermedad es mayoritariamente joven y con escasa comorbilidad, también puede presentarse en pacientes de edad avanzada con enfermedades asociadas de riesgo. Es un acto quirúrgico que no debe considerarse menor, a pesar de su brevedad y sencillez de su ejecución en la mayoría de los casos. La posibilidad de desarrollo de complicaciones postoperatorias no es irrelevante, ya que se trata de un proceso séptico intraperitoneal. Los retrasos en el diagnóstico o en el tratamiento condicionan la presentación de apendicitis evolucionadas con peritonitis difusa o localizada.

De este modo, se entiende que debido a las condiciones en que el paciente sea intervenido quirúrgicamente, podrá llegar a presentar fallas de cicatrización post operatorio, pues, la herida inicia un proceso de inflamación, enrojecimiento y algunos momentos se observa la expulsión de líquidos o pus, que origina fiebre y dolor en la cicatriz. Ante estos síntomas, es importante recurrir al médico con el fin de recibir la respectiva atención que le permita al paciente ayudarle 


\section{Cirugía de apendicitis problemas de cicatrización}

Vol. 3, núm. 1., (2019)

María Cristina Alcívar Fabre; Alfredo Enrique Galindo Veliz; Gianella Lissette Cruz Rambay; Pablo Marcelo Armas Ramírez

mediante la utilización de nuevas intervenciones quirúrgicas, para limpiar la cavidad abdominal o simplemente colocar drenajes que ayudan a la expulsión de los líquidos encontrados y así lograr su respectiva recuperación.

Finalmente, se puede indicar que una infección quirúrgica puede originarse en una cirugía séptica o en una cirugía aséptica. Puede ser endoinfección o exoinfección, monobacteriana o polibacteriana, toxígena, nicótica o mixta. En relación a la endoinfección quirúrgica a la sepsis focal o general producida a raíz de una cirugía séptica o aséptica, por invasión de los agentes correspondientes a las cepas indígenas que pueblan la encrucijada aerodigestiva, enterocolónica o vía genitourinaria baja, que adquieren protopatogenicidad por el acto quirúrgico o ciertas terapéuticas o modificaciones del terreno o estados clínicos especiales, para llegar a producir cuadros sépticos mono o polibacterianos o micopatías localizadas o generalizadas.

\section{Bibliografía.}

Altrudi, C. (2017). Apendicitis. Complicaciones: Infección de la Vida. IntraMed, 25.

Kerlinger, H. (2015). Método Científico. Madrid: Paidós.

Médica, E. (2016). España: Oceáno .

Molina, F. (2018). Uso del Drenaje después de una Apendcetomía Abierta. Biblioteca Cochrane, 12-18.

Montes, I. (2018). Apendicitis. Mayo Clinc, 8.

Padrino, J. (2017). Infecciones Bacterianas . Scielo, 22.

Salvatierra, G. (2018). Infecciones de Heridas Quirúrgicas. Tratamiento. MedinePlus, 6.

Zambrano, P. (2018). Método Científico . México: Fondo Educativo Interamericano. 